\title{
Femoral histology and growth patterns of the ceratopsian dinosaur Psittacosaurus sibiricus from the Early Cretaceous of Western Siberia
}

Pavel P. Skutschas, Semyon S. Morozov, Alexander O. Averianov, Sergey V. Leshchinskiy, Stepan V. Ivantsov, Alexey V. Fayngerts, Olga A. Feofanova, Olga N. Vladimirova and Dmitry A. Slobodin Acta Palaeontologica Polonica 66 (2), 2021: 437-447 doi:https://doi.org/10.4202/app.00819.2020

The early ceratopsian dinosaur Psittacosaurus sibiricus from the Early Cretaceous of Western Siberia, Russia, is one of the most advanced and largest (up to $2.5 \mathrm{~m}$ ) members of the genus. Here we present a description of ontogenetic changes in the long-bone histology of this species. Analysis of a growth series of femora demonstrates significant histological maturation during ontogeny, expressed by the progressive appearance of signs of bone remodeling (erosion bays, secondary bone formation), decreasing of vascularity, changing of the orientation of vascular canals from reticular to longitudinal, and appearance of parallel-fibred bone in the outer part cortex. These ontogenetic changes in the longbone histology of $P$. sibiricus are generally similar to those of another relatively advanced species, $P$. lujiatunensis from China. The basal $P$. mongoliensis from Mongolia shows less mature long-bone histology during late ontogeny (e.g., the late appearance of signs of remodeling and the predominance of reticular vascularization at later stages). We suggest that the earlier achievement of histological maturity is an evolutionary trend of the genus Psittacosaurus.

Key words: Dinosauria, Ceratopsia, Psittacosaurus, bone histology, Cretaceous, Siberia, Russia.

Pavel P. Skutschas [skutchas@mail.ru; p.skutschas@spbu.ru] and

Semyon S. Morozov [semyon-morozow7@yandex.ru], Vertebrate Zoology

Department, Saint Petersburg State University, Universitetskaya nab. 7/9, 199034

Saint Petersburg, Russia. Alexander O. Averianov [dzharakuduk@ mail.ru], Zoological Institute of the Russian Academy of Sciences, Universitetskaya nab. 1, 199034 Saint Petersburg, Russia. Stepan V. Ivantsov [stepan ivantsov@mail.ru], Laboratory of Micropaleontology, Tomsk State University, Prospekt Lenina 36, 634050, Tomsk, Russia. Sergey V. Leshchinskiy [1@ggf.tsu.ru] and Alexey V. Fayngerts [alex@ggf.tsu.ru ], Laboratory of Mesozoic and Cenozoic Continental Ecosystems, Tomsk State University, Prospekt Lenina 36, 634050, Tomsk, Russia. Olga A. Feofanova [feofanova42@yandex.ru ], Olga N. Vladimirova [ovlad-5@mail.ru], and Dmitry A. Slobodin [d.a.slobodin@mail.ru], Kuzbass State Museum of Local Lore, Prospekt Sovetskiy 51, 650000, Kemerovo, Russia. 
This is an open-access article distributed under the terms of the Creative Commons

Attribution License (for details please see creativecommons.org), which permits unrestricted use, distribution, and reproduction in any medium, provided the original author and source are credited.

FarF Full text $(3,901.8 \mathrm{kB})$ 